\title{
Tepidicella xavieri gen. nov., sp. nov., a betaproteobacterium isolated from a hot spring runoff
}

\author{
Luis França, ${ }^{1}$ Fred A. Rainey, ${ }^{2}$ M. Fernanda Nobre ${ }^{3}$ and Milton S. da Costa ${ }^{1}$ \\ 'Departamento de Bioquímica, Universidade de Coimbra, 3001-401 Coimbra, Portugal \\ ${ }^{2}$ Department of Biological Sciences, Louisiana State University, Baton Rouge, LA 70803, USA \\ ${ }^{3}$ Departamento de Zoologia, Universidade de Coimbra, 3004-517 Coimbra, Portugal
}

\begin{abstract}
Strains TU-16 $6^{\top}$ and TU-18, two non-pigmented bacterial isolates with an optimum growth temperature of about $45^{\circ} \mathrm{C}$ and an optimum $\mathrm{pH}$ of about $8 \cdot 5-9 \cdot 0$, were recovered from the Furnas geothermal area on the Island of São Miguel in the Azores. Phylogenetic analysis of the 16S rRNA gene sequence of these strains indicated that they represent a novel species in a new genus of the phylum Betaproteobacteria. The major fatty acids of strains TU- $16^{\top}$ and TU-18 were $16: 0$ and $18: 1 \omega 7 c$. Ubiquinone 8 was the major respiratory quinone and the major polar lipids were phosphatidylethanolamine and phosphatidylglycerol. The novel isolates were aerobic; thiosulfate was oxidized to sulfate in the presence of a metabolizable carbon source. The organism assimilated organic acids and amino acids, but did not assimilate carbohydrates or polyols. Based on phylogenetic analyses and physiological and biochemical characteristics, it is proposed that strain TU-16 ${ }^{\top}$ (=LMG $23030^{\top}=$ CIP $108724^{\top}$ ) represents the type strain of a novel species in a new genus, Tepidicella xavieri gen. nov., sp. nov.
\end{abstract}

Three slightly thermophilic species of betaproteobacteria named Tepidimonas ignava (Moreira et al., 2000), Tepidimonas aquatica (Freitas et al., 2003) and 'Tepidimonas taiwanensis' (Chen et al., 2006) have been described recently. Two related strains, designated AA-1 and AA-2, have also been isolated recently from Aachen in Germany (Albuquerque et al., 2006). These organisms were all isolated from hot springs and an industrial hot water tank. A strain designated SMC-6271 and named 'Tepidimonas arfidensis', which represents an additional lineage within the genus Tepidimonas, was isolated from the bone marrow of a person with leukaemia, but this organism appears to represent a contaminant of the sample (Ko et al., 2005). The species of this genus have optimum growth temperatures of about $50{ }^{\circ} \mathrm{C}$, do not assimilate carbohydrates or polyols, do not grow at pH below $6 \cdot 0$ or above $9 \cdot 5$ and oxidize thiosulfate to sulfate in the presence of an assimilable carbon source.

Two strains, TU-16 ${ }^{\mathrm{T}}$ and TU-18, with identical $16 \mathrm{~S}$ rRNA gene sequences, were isolated recently from the Furnas geothermal area on the Island of São Miguel in the Azores; they represent a new lineage closely related to the genus Tepidimonas. The organisms share many physiological and

Published online ahead of print on 23 December 2005 as DOI 10.1099/ijs.0.64193-0.

The GenBank/EMBL/DDBJ accession number for the $16 \mathrm{~S}$ rRNA gene sequence of strain $\mathrm{TU}-16^{\top}$ is $\mathrm{DQ} 295805$. biochemical characteristics with species of the genus Tepidimonas, but have a distinctly lower temperature range and a higher $\mathrm{pH}$ range for growth. Based on these characteristics and phylogenetic analysis, it is proposed that these strains represent a novel species in a new genus for which the name Tepidicella xavieri gen. nov., sp. nov. is recommended.

Strains TU- $16^{\mathrm{T}}$ and TU-18 were isolated from a hot spring runoff at Furnas (temperature of $70{ }^{\circ} \mathrm{C}$ and $\mathrm{pH} 7 \cdot 5$ ). Water samples were transported without temperature control and filtered through membrane filters. The filters were placed on the surface of agar-solidified Thermus medium (Williams \& da Costa, 1992), wrapped in plastic bags and incubated at $50{ }^{\circ} \mathrm{C}$ for up to 4 days. Cultures were maintained as described previously (Moreira et al., 2000). Culturing in Degryse 162 medium (Degryse et al., 1978) was later adopted because it resulted in higher growth yields. Tepidimonas ignava SPS- $1037^{\mathrm{T}}\left(=\mathrm{DSM} 12034^{\mathrm{T}}\right)$, Tepidimonas aquatica CLN $-1^{\mathrm{T}}\left(=\mathrm{DSM} 14833^{\mathrm{T}}=\right.$ ATCC BAA-469 $\left.{ }^{\mathrm{T}}\right)$, 'Tepidimonas taiwanensis' I1-1 (=BCRC $17406=\mathrm{LMG} 22826)$ and strain AA-1 (=LMG 23094=CIP 108777) were used as controls.

Unless otherwise stated, all morphological examinations and biochemical and tolerance tests were performed as described previously (Santos et al., 1989; Nunes et al., 1992) in Degryse 162 liquid medium or Degryse 162 agar at $\mathrm{pH} 8 \cdot 0$ and at $45^{\circ} \mathrm{C}$ for up to 5 days. The growth temperature range of the strains in liquid Degryse 162 medium was examined 
in a reciprocal water-bath shaker between 20 and $60^{\circ} \mathrm{C}$. The $\mathrm{NaCl}$ range for growth of the organisms was determined at $45^{\circ} \mathrm{C}$. The range for growth was determined at $45^{\circ} \mathrm{C}$ in the same medium between $\mathrm{pH} 6$ and 11 using $50 \mathrm{mM}$ MES, HEPES, TAPS CAPSO and CAPS.

Single-carbon source assimilation tests were performed in a minimal medium composed of Degryse 162 basal salts with yeast extract $\left(0 \cdot 1 \mathrm{~g} \mathrm{l}^{-1}\right)$ to which filter-sterilized ammonium chloride $\left(0.5 \mathrm{~g} \mathrm{l}^{-1}\right)$, a vitamin, nucleotide and amino acid mixture (Sharp \& Williams, 1988), and the carbon source $\left(2 \cdot 0 \mathrm{~g} \mathrm{l}^{-1}\right)$ were added. Growth of the strains was examined by measuring the turbidity of cultures incubated at $45^{\circ} \mathrm{C}$ in $20 \mathrm{ml}$ screw-capped tubes containing $10 \mathrm{ml}$ medium for up to 5 days. Fermentation was tested using the API 50 CHL system (bioMérieux), as recommended by the manufacturer, incubated at $45^{\circ} \mathrm{C}$ for up to 5 days. The ability of the strains to grow with several electron acceptors was examined in a defined basal medium described previously (Kieft et al., 1999) at $45^{\circ} \mathrm{C}$ and $\mathrm{pH} 8.5$. Lactate $(30 \mathrm{mM})$ was used as the electron donor to examine growth under an $\mathrm{N}_{2}$ atmosphere coupled to the reduction of nitrate, nitrite, $\mathrm{Fe}(\mathrm{III})-\mathrm{NTA}$, fumarate, sulfate and thiosulfate (each at $10 \mathrm{mM}$, except nitrite, which was at $1.0 \mathrm{mM}$ ). Control cultures lacking an electron acceptor were also tested for growth.

Aerobic growth on reduced sulfur compounds was tested in modified medium 69 (www.dsmz.de/media/med069.htm) containing the following components $\left(1^{-1}\right): \mathrm{Na}_{2} \mathrm{HPO}_{4} \cdot 12 \mathrm{H}_{2} \mathrm{O}$, $10.6 \mathrm{~g} ; \mathrm{KH}_{2} \mathrm{PO}_{4}, 1.5 \mathrm{~g} ; \mathrm{NH}_{4} \mathrm{Cl}, 0.3 \mathrm{~g}$; yeast extract, $1.0 \mathrm{~g}$; $\mathrm{MgCl}_{2}, 0 \cdot 1 \mathrm{~g}$; and trace element solution of medium 27 (www.dsmz.de/media/med027.htm). Cysteine, thiosulfate and tetrathionate were added to the medium at concentrations of $0 \cdot 1-1 \cdot 0 \mathrm{~g} \mathrm{l}^{-1}$ (Moreira et al., 2000; Freitas et al., 2003). Levels of thiosulfate and sulfate in the supernatants were determined using the methods described by Westley (1987) and Sörbo (1987), respectively.

Isolates $\mathrm{TU}-16^{\mathrm{T}}$ and $\mathrm{TU}-18$ formed round, creamy-white colonies. Cells were rod-shaped, $0 \cdot 5-1 \cdot 0 \mu \mathrm{m}$ in width by $1 \cdot 0-2 \cdot 0 \mu \mathrm{m}$ in length and were motile by one polar flagellum. The optimum growth temperature was about $45^{\circ} \mathrm{C}$; growth was observed between about 25 and $55^{\circ} \mathrm{C}$ (Table 1). Type strains of species of the genus Tepidimonas had higher optimum growth temperatures (around $50^{\circ} \mathrm{C}$ ), did not grow at $25^{\circ} \mathrm{C}$ and, with the exception of Tepidimonas ignava, did not grow above $60^{\circ} \mathrm{C}$. The optimum $\mathrm{pH}$ for growth of the novel isolates was $8 \cdot 5-9 \cdot 0$; growth was not observed below $\mathrm{pH} 6 \cdot 5$ or above $10 \cdot 5$. Type strains of species of the genus Tepidimonas had lower $\mathrm{pH}$ ranges for growth, i.e. between about pH 6.0 and 9.5 (Moreira et al., 2000; Freitas et al., 2003; Albuquerque et al., 2006). DNase and urease activities were detected, but amylase and xylanase were not detected. Aesculin, hippurate and Tween 20 were hydrolysed.

The novel isolates were unable to grow on any of the carbohydrates and polyols tested. On the other hand, they utilized the majority of the organic acids and amino acids tested. Fermentation of carbohydrates was not observed. Nitrate, nitrite, $\mathrm{Fe}(\mathrm{III})-\mathrm{NTA}$, fumarate, sulfate and thiosulfate were not used as electron acceptors under anaerobic conditions. L-Cysteine, thiosulfate and tetrathionate did not lead to an increase in the biomass of strains TU-16 ${ }^{\mathrm{T}}$ and TU-18, but were oxidized to sulfate.

For polar lipid analysis, cells were grown in 11 Erlenmeyer flasks containing $200 \mathrm{ml}$ Degryse 162 medium at $45^{\circ} \mathrm{C}$ in a water-bath shaker until the exponential phase of growth. Harvesting of the cultures, extraction of lipids and their separation were performed as described previously (Prado et al., 1988; Donato et al., 1990). Lipoquinones were extracted from freeze-dried cells and purified by TLC as described previously (Tindall, 1989; Moreira et al., 2000; Freitas et al., 2003). Cultures for fatty acid analysis were grown on plates of Degryse 162 medium in sealed plastic bags submerged in a water-bath at $50{ }^{\circ} \mathrm{C}$ for $24 \mathrm{~h}$. Fatty acid methyl esters were obtained from fresh wet biomass; their identification and quantification, as well as numerical analysis of the fatty acid profiles, were performed using the standard MIS library Generation Software (Microbial ID).

Phosphatidylethanolamine and phosphatidylglycerol dominated the polar lipid profiles of strains TU-16 ${ }^{\mathrm{T}}$ and TU-18, which were similar to those of the type strains of members of the genus Tepidimonas. Ubiquinone 8 was the major respiratory quinone. The fatty acid composition of strains $\mathrm{TU}-16^{\mathrm{T}}$ and TU-18 was characterized by very large relative proportions of $16: 0$, which reached about $45 \%$ of the total, and $18: 1 \omega 7 c$, which reached levels of about $20 \%$ (Table 2).

DNA for the determination of the $\mathrm{G}+\mathrm{C}$ content was isolated as described by Nielsen et al. (1995). The DNA $\mathrm{G}+\mathrm{C}$ content was determined by HPLC as described by Mesbah et al. (1989). Extraction of genomic DNA for $16 \mathrm{~S}$ rRNA gene sequence determination, PCR amplification of the $16 \mathrm{~S}$ rRNA gene and sequencing of purified PCR products were carried out as described previously (Rainey et al., 1996). Purified reactions were electrophoresed using a model 310 Genetic Analyser (Applied Biosystems). The 16S rRNA gene sequences were aligned against representative reference sequences of members of the Betaproteobacteria lineage using MEGA version 3.1 (Kumar et al., 2004). The method of Jukes \& Cantor (1969) was used to calculate evolutionary distances. Phylogenetic dendrograms and bootstrap analyses were generated using various algorithms contained in the PHYLIP package (Felsenstein, 1993).

The DNA G + C contents of strains TU- $16^{\mathrm{T}}$ and TU-18 were 64.9 and $65.5 \mathrm{~mol} \%$, respectively. These values are about 3 mol\% lower than those of species of the genus Tepidimonas. Strains TU- $16^{\mathrm{T}}$ and TU-18 had identical $16 \mathrm{~S}$ rRNA gene sequences over the $1480 \mathrm{nt}$ that were determined and compared. A comparative analysis of $1393 \mathrm{nt}$ positions of the 16S rRNA gene sequence of strain TU-16 ${ }^{\mathrm{T}}$ with those of other members of the Betaproteobacteria lineage showed that strain TU- $16^{\mathrm{T}}$ was closely related $(99 \cdot 7$ and $99 \cdot 5 \%$ similarity) to sequences of two environmental clones 


\section{Table 1. Characteristics that distinguish strains $T U-16^{\top}$ and $T U-18$ from related strains/species}

Strains: 1, Tepidicella xavieri sp. nov. strains TU-16 ${ }^{\mathrm{T}}$ and TU-18; 2, strain AA-1; 3, Tepidimonas ignava SPS-1037 ${ }^{\mathrm{T}}$;, Tepidimonas aquatica CLN-1 ${ }^{\mathrm{T}}$; 5, 'Tepidimonas taiwanensis' I1-1; 6, 'Tepidimonas arfidensis' SMC-6271. -, Negative; +, positive; W, weakly positive; ND, not determined. Strains TU-16 ${ }^{\mathrm{T}}$, TU-18, AA-1, SPS- $1037^{\mathrm{T}}$ and CLN-1 ${ }^{\mathrm{T}}$ hydrolysed hippurate; none of these strains hydrolysed arbutin or xylan. All organisms were oxidase-positive. Strains TU-16 ${ }^{\mathrm{T}}$, TU-18, AA-1, SPS-1037 ${ }^{\mathrm{T}}$, CLN-1 ${ }^{\mathrm{T}}$ and I1-1 were positive for alkaline phosphatase, esterase (C4), lipase (C8), leucine arylamidase, valine arylamidase and naphthol-AS-BI-phosphohydrolase; these strains were all negative for cystine arylamidase, trypsin, $\alpha$-chymotrypsin, $\alpha$-galactosidase, $\beta$-galactosidase, $\beta$-glucuronidase, $\alpha$-glucosidase, $\beta$-glucosidase, $N$-acetyl- $\beta$ glucosaminidase, $\alpha$-mannosidase and $\alpha$-fucosidase. Strains TU-16 ${ }^{\mathrm{T}}$, TU-18, AA-1, SPS-1037 ${ }^{\mathrm{T}}, \mathrm{CLN}-1^{\mathrm{T}}$ and I1-1 assimilated succinate, acetate, lactate, pyruvate, L-ornithine, L-proline, L-alanine, L-asparagine, L-glutamate and L-glutamine; none of them assimilated lactose, D-arabinose, D-ribose, glycerol, D-mannitol, ribitol, xylitol, sorbitol, myo-inositol, benzoate, glycine, L-valine, L-methionine or L-threonine.

\begin{tabular}{|c|c|c|c|c|c|c|}
\hline Characteristic & 1 & 2 & 3 & 4 & $5^{*}$ & $6 \dagger$ \\
\hline \multicolumn{7}{|l|}{ Temperature $\left({ }^{\circ} \mathrm{C}\right)$ for growth: } \\
\hline Range & $25-55$ & $30-60$ & $30-65$ & $30-60$ & $35-60$ & ND \\
\hline \multicolumn{7}{|l|}{$\mathrm{pH}$ for growth: } \\
\hline Range & $6 \cdot 5-10 \cdot 5$ & $6 \cdot 0-9 \cdot 5$ & $6 \cdot 0-9 \cdot 5$ & $6 \cdot 0-9 \cdot 5$ & $6 \cdot 0-8 \cdot 0$ & ND \\
\hline \multicolumn{7}{|l|}{ Presence of: } \\
\hline Catalase & + & + & + & + & $-(\mathrm{w})$ & ND \\
\hline DNase & + & + & + & + & $\mathrm{ND}$ & ND \\
\hline Urease & + & ND & + & - & - & - \\
\hline Lipase (C14) & $\mathrm{W} /+$ & - & - & - & + & $\mathrm{ND}$ \\
\hline Starch & - & - & - & - & $+(-)$ & ND \\
\hline Tween 20 & + & + & - & + & $\mathrm{ND}$ & ND \\
\hline Tween 40 & - & - & - & + & $\mathrm{ND}$ & ND \\
\hline Tween 60 & - & + & - & + & - & $\mathrm{ND}$ \\
\hline Tween 80 & - & - & - & + & - & ND \\
\hline \multicolumn{7}{|l|}{ Assimilation of: } \\
\hline D-Glucose & - & - & - & - & $+(+)$ & - \\
\hline D-Fructose & - & - & - & - & $-(+)$ & ND \\
\hline Citrate & + & - & - & - & $+(+)$ & - \\
\hline Malate & + & - & + & - & $+(+)$ & - \\
\hline 2-Oxoglutarate & + & - & + & + & $+(+)$ & ND \\
\hline L-Tyrosine & + & ND & - & - & ND & ND \\
\hline L-Isoleucine & - & + & + & + & $\mathrm{ND}(-)$ & ND \\
\hline L-Arginine & - & - & - & - & $\mathrm{ND}(+)$ & ND \\
\hline L-Cysteine & - & - & - & - & $\mathrm{ND}$ & $\mathrm{ND}$ \\
\hline Reduction of $\mathrm{NO}_{3}^{-}$to $\mathrm{NO}_{2}^{-}$ & - & - & - & + & + & + \\
\hline $\mathrm{G}+\mathrm{C}$ content $(\mathrm{mol} \%)$ & $64 \cdot 9 / 65 \cdot 5$ & $67 \cdot 8$ & $69 \cdot 7$ & $68 \cdot 6$ & $68 \cdot 1$ & $69 \cdot 2$ \\
\hline
\end{tabular}

${ }^{*}$ Data from Chen et al. (2006) are shown; data from this study are given in parentheses.

$\dagger$ Data from Ko et al. (2005). 
Table 2. Mean fatty acid content (\%) of strains $\mathrm{TU}-16^{\mathrm{T}}$ and $\mathrm{TU}-18$ and related strains/species grown at $50{ }^{\circ} \mathrm{C}$

Strains: 1, Tepidicella xavieri strains TU-16 ${ }^{\mathrm{T}}$ and TU-18; 2, strain AA-1; 3, Tepidimonas ignava SPS-1037 ${ }^{\mathrm{T}}$ 4, Tepidimonas aquatica CLN-1 ${ }^{\mathrm{T}}$; 5, 'Tepidimonas taiwanensis' I1-1; 6, 'Tepidimonas arfidensis' SMC-6271. -, Fatty acids present at levels of less than $0 \cdot 5 \%$ or not detected. ECL, equivalent chain-length.

\begin{tabular}{|c|c|c|c|c|c|c|}
\hline Fatty acid & 1 & 2 & 3 & 4 & 5 & $6^{*}$ \\
\hline $8: 03-\mathrm{OH}$ & $0 \cdot 9 \pm 0 \cdot 1$ & $0 \cdot 5 \pm 0 \cdot 1$ & $0 \cdot 7 \pm 0 \cdot 1$ & - & - & - \\
\hline $10: 0$ & $0 \cdot 6 \pm 0 \cdot 1$ & - & - & - & - & - \\
\hline $12: 0$ & $1 \cdot 5 \pm 0 \cdot 1$ & - & - & - & - & - \\
\hline $15: 1 \omega 6 c$ & - & $3 \cdot 0 \pm 0 \cdot 3$ & $3 \cdot 7 \pm 1 \cdot 5$ & - & $0 \cdot 6 \pm 0 \cdot 1$ & - \\
\hline $15: 0$ & $0 \cdot 7 \pm 0 \cdot 1$ & $5 \cdot 1 \pm 0 \cdot 6$ & $6 \cdot 2 \pm 0 \cdot 7$ & $0 \cdot 5 \pm 0 \cdot 1$ & $0 \cdot 9 \pm 0 \cdot 1$ & $1 \cdot 0$ \\
\hline $16: 0$ iso & $1 \cdot 6 \pm 0 \cdot 1$ & - & - & $0 \cdot 8 \pm 0 \cdot 1$ & - & - \\
\hline $16: 1 \omega 7 c$ & $6 \cdot 8 \pm 0 \cdot 2$ & $27 \cdot 4 \pm 1 \cdot 1$ & $24 \cdot 3 \pm 0 \cdot 5$ & $11 \cdot 1 \pm 5 \cdot 1$ & $22 \cdot 2 \pm 0 \cdot 1$ & $16 \cdot 7$ \\
\hline $16: 0$ & $44 \cdot 5 \pm 0 \cdot 1$ & $32 \cdot 9 \pm 0 \cdot 6$ & $23 \cdot 2 \pm 3 \cdot 4$ & $42 \cdot 5 \pm 0 \cdot 6$ & $42 \cdot 8 \pm 0 \cdot 2$ & $51 \cdot 3$ \\
\hline Unknown (ECL 16•090) & - & - & - & $0 \cdot 8 \pm 0 \cdot 3$ & - & - \\
\hline Unknown (ECL 16·559) & $1 \cdot 1 \pm 0 \cdot 1$ & - & - & - & - & - \\
\hline $17: 1 \omega 8 c$ & - & - & $1 \cdot 0 \pm 0 \cdot 1$ & - & - & - \\
\hline $17: 1 \omega 6 c$ & - & - & $3 \cdot 1 \pm 0 \cdot 7$ & - & - & - \\
\hline $17: 0$ cyclo & $11 \cdot 9 \pm 0 \cdot 1$ & $7 \cdot 0 \pm 3 \cdot 2$ & - & $33 \cdot 2 \pm 3 \cdot 5$ & $7 \cdot 0 \pm 0 \cdot 1$ & $17 \cdot 2$ \\
\hline $17: 0$ & $1 \cdot 8 \pm 0 \cdot 3$ & $8 \cdot 5 \pm 1 \cdot 1$ & $19 \cdot 9 \pm 3 \cdot 9$ & $3 \cdot 2 \pm 0 \cdot 4$ & $4 \cdot 5 \pm 0 \cdot 3$ & $2 \cdot 7$ \\
\hline $18: 1 \omega 7 c$ & $20 \cdot 8 \pm 0 \cdot 9$ & $10 \cdot 0 \pm 1 \cdot 2$ & $11 \cdot 9 \pm 1 \cdot 8$ & - & $18 \cdot 4 \pm 0 \cdot 2$ & $6 \cdot 6$ \\
\hline $18: 0$ & $2 \cdot 4 \pm 0 \cdot 1$ & $1 \cdot 2 \pm 0 \cdot 1$ & $2 \cdot 2 \pm 0 \cdot 8$ & $4 \cdot 9 \pm 0 \cdot 2$ & $2 \cdot 5 \pm 0 \cdot 1$ & $1 \cdot 6$ \\
\hline Unknown (ECL 18·082) & $0 \cdot 7 \pm 0 \cdot 2$ & $1 \cdot 3 \pm 0 \cdot 6$ & $3 \cdot 2 \pm 1 \cdot 7$ & - & - & - \\
\hline Unknown (ECL 18·422) & $0 \cdot 9 \pm 0 \cdot 2$ & - & - & $1 \cdot 0 \pm 0 \cdot 3$ & - & - \\
\hline Unknown (ECL 18·824) & $0 \cdot 7 \pm 0 \cdot 3$ & - & $0 \cdot 7 \pm 0 \cdot 2$ & - & - & - \\
\hline $19: 0$ cyclo $\omega 8 c$ & $4 \cdot 6 \pm 0 \cdot 9$ & - & - & - & $0 \cdot 5 \pm 0 \cdot 1$ & $1 \cdot 1$ \\
\hline
\end{tabular}

${ }^{\star}$ Data from Ko et al. (2005).

recovered from a deep terrestrial fracture system (AY768824) and a gold mine borehole (AY796039) (Fig. 1). Of cultured taxa with validly described names, species of the genus Tepidimonas had highest $16 \mathrm{~S}$ rRNA gene sequence similarity (94.6-95.5\%; Fig. 1) to strain TU-16 ${ }^{\mathrm{T}}$. The relationship to species of other genera of the Betaproteobacteria lineage was below $95 \%$. The phylogenetic relationship between strain $\mathrm{TU}-16^{\mathrm{T}}$ and species of the genus Tepidimonas is supported by a bootstrap value of $97 \%$, whereas the individual lineages comprising strain $\mathrm{TU}-16^{\mathrm{T}}$ and related clone sequences and that of the Tepidimonas species cluster are both supported by $100 \%$ bootstrap values, thus indicating their distinctiveness. This is in contrast to the stability of the branching order within the Tepidimonas species cluster, where some branching points have low statistical support.

Species of the genus Tepidimonas and strains TU-16 ${ }^{\mathrm{T}}$ and TU-18 have rather homogeneous phenotypic characteristics indicating a close relationship. Strains TU- $16^{\mathrm{T}}$ and TU-18 can be distinguished from the type strains of Tepidimonas species by differences in carbon source assimilation and fatty acid composition. These differences could, by themselves, indicate that strains TU-16 ${ }^{\mathrm{T}}$ and TU-18 represent a novel species of the genus Tepidimonas. However, strains TU-16 ${ }^{\mathrm{T}}$ and TU-18 can be distinguished from species of the genus Tepidimonas by their lower temperature range and higher $\mathrm{pH}$ range for growth. Strain SMC-6271 named 'Tepidimonas arfidensis', in common with other members of the genus, also has an optimum growth temperature of about $50^{\circ} \mathrm{C}$, a $\mathrm{pH}$ optimum for growth of about $7 \cdot 0$ and does not utilize glucose; however, few characteristics of this strain have been reported, making it very difficult to compare phenotypic characteristics of this organism with those of other species of the genus Tepidimonas or strains TU-16 ${ }^{\mathrm{T}}$ and TU-18 (Ko et al., 2005).

The ecological significance of the isolation of strains TU-16 ${ }^{\mathrm{T}}$ and TU-18 from a neutral $\mathrm{pH}$ hot spring and their close phylogenetic relationship to environmental 16S rRNA gene clones from deep gold mines or fractures cannot be explained at this time. Perhaps environments with similar physico-chemical parameters exist at these subsurface sites. The lower DNA G + C contents, grouping within a distinct phylogenetic lineage, the lower growth temperature range and the higher $\mathrm{pH}$ range of strains $\mathrm{TU}-16^{\mathrm{T}}$ and TU-18 indicate that these strains belong to a novel species in a new genus for which the name Tepidicella xavieri gen. nov., sp. nov. is proposed.

\section{Description of Tepidicella gen. nov.}

Tepidicella (Te.pi.di.cel'la. L. adj. tepidus warm; L. fem. n. cella chamber/cell; N.L. fem. n. Tepidicella a cell living in a warm environment). 


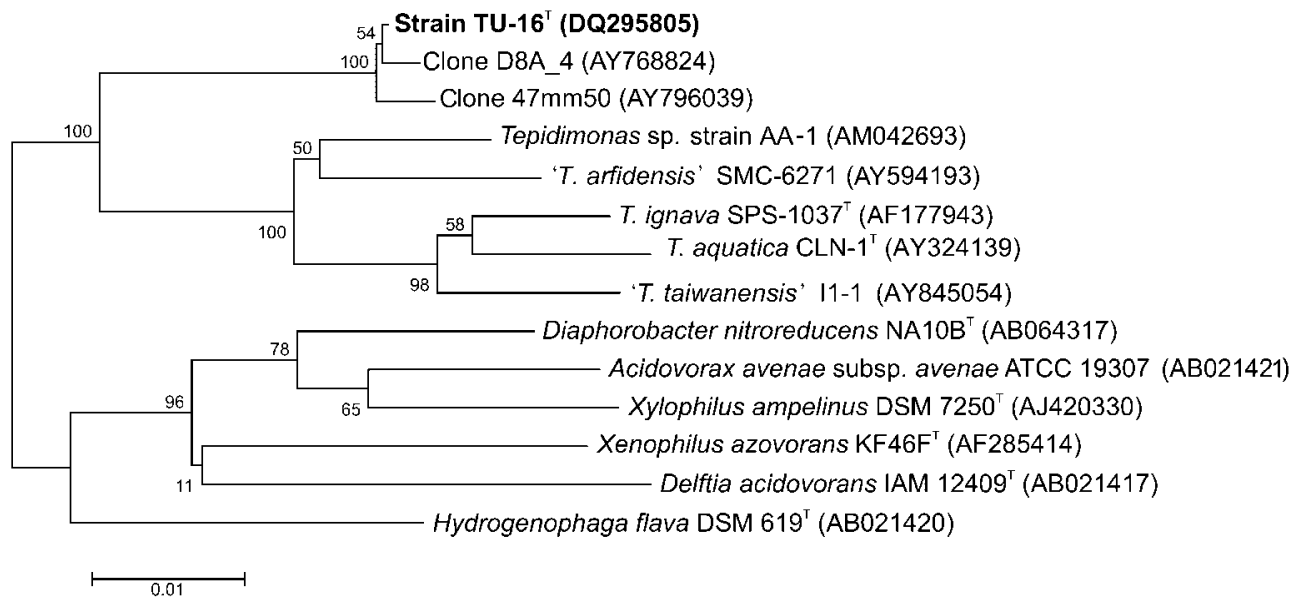

Fig. 1. Phylogeny based on $16 \mathrm{~S}$ rRNA gene sequences showing the relationships of strain TU-16 ${ }^{\top}$ and related taxa. The dendrogram was constructed from distance matrices using the neighbour-joining method. Numbers at branching points represent bootstrap values from 1000 replicates. Bar, 1 inferred nucleotide substitution per 100 nucleotides.

Forms motile rod-shaped cells that stain Gram-negative. Endospores are not formed. Slightly thermophilic and slightly alkaliphilic. Strictly aerobic; oxidase- and catalasepositive. Fatty acids are straight-chained; major phospholipids are phosphatidylethanolamine and phosphatidylglycerol; ubiquinone 8 is the major respiratory quinone. Reduced sulfur compounds are oxidized to sulfate. Organic acids and amino acids are used as carbon and energy sources, but sugars and polyols are not assimilated. The genus Tepidicella belongs to the Betaproteobacteria. The type species is Tepidicella xavieri.

\section{Description of Tepidicella xavieri sp. nov.}

Tepidicella xavieri (xa.vi.e'ri. N.L. gen. n. xavieri of Xavier, in honour of the Portuguese biochemist António V. Xavier).

Forms short rod-shaped cells, $0 \cdot 5-1 \cdot 0 \times 1 \cdot 0-2 \cdot 0 \mu \mathrm{m}$. Gram stain is negative. Motile by one polar flagellum. Colonies on Degryse 162 medium are creamy-white. Growth occurs between 25 and $55^{\circ} \mathrm{C}$; the optimum growth temperature for the type strain is about $45^{\circ} \mathrm{C}$. Optimum $\mathrm{pH}$ for growth is $8 \cdot 5-9 \cdot 0$; growth does not occur below $\mathrm{pH} 6 \cdot 5$ or above $\mathrm{pH} 10 \cdot 5$. Major fatty acids are $16: 0$ and $18: 1 \omega 7 c$. Ubiquinone 8 is the major respiratory quinone. Strain $\mathrm{TU}-16^{\mathrm{T}}$ is strictly aerobic and chemo-organotrophic. Strain $\mathrm{TU}-16^{\mathrm{T}}$ does not reduce nitrate to nitrite. Thiosulfate is oxidized to sulfate in the presence of a carbon source. Positive for cytochrome oxidase, catalase, urease and DNase. Aesculin, hippurate and Tween 20 are degraded. Several amino acids and organic acids are utilized for growth, but the type strain does not utilize hexoses, disaccharides, pentoses or polyols.

The type strain is TU-16 $6^{\mathrm{T}}\left(=\mathrm{LMG} 23030^{\mathrm{T}}=\mathrm{CIP} 108724^{\mathrm{T}}\right)$, isolated from a hot spring runoff in Furnas, the Azores; it has a DNA G + C content of $64 \cdot 9 \mathrm{~mol} \%$.

\section{Acknowledgements}

This work was supported in part by POCTI 35029/99, Portugal. F. A. R. was in part supported by NSF award MCB 9977882. We are indebted to Professor J. Euzéby (École National Vétérinaire, Toulouse, France) for the etymology of the new organism's name.

\section{References}

Albuquerque, L., Tiago, I., Veríssimo, A. \& da Costa, M. S. (2006). Tepidimonas thermarum sp. nov., a new slightly thermophilic betaproteobacterium isolated from the Elisenquelle in Aachen. Syst Appl Microbiol (in press).

Chen, T. L., Chou, Y. J., Chen, W. M., Arun, B. \& Young, C. C. (2006). Tepidimonas taiwanensis sp. nov., a novel alkaline-protease-producing bacterium isolated from a hot spring. Extremophiles (in press) (DOI: 10.1007/s00792-005-0469-9).

Degryse, E., Glansdorff, N. \& Pierard, A. (1978). A comparative analysis of extreme thermophilic bacteria belonging to the genus Thermus. Arch Microbiol 117, 189-196.

Donato, M. M., Seleiro, E. A. \& da Costa, M. S. (1990). Polar lipid and fatty acid composition of strains of the genus Thermus. Syst Appl Microbiol 13, 234-239.

Felsenstein, J. (1993). PHYLIP (phylogenetic inference package) version 3.5.1. Department of Genetics, University of Washington, Seattle, USA.

Freitas, M., Rainey, F. A., Nobre, M. F., Silvestre, A. J. D. \& da Costa, M. S. (2003). Tepidimonas aquatica sp. nov., a new slightly thermophilic beta-proteobacterium isolated from a hot water tank. Syst Appl Microbiol 26, 376-381.

Jukes, T. H. \& Cantor, C. R. (1969). Evolution of protein molecules. In Mammalian Protein Metabolism, vol. 3, pp. 21-132. Edited by H. N. Munro. New York: Academic Press.

Kieft, T. L., Fredrickson, J. K., Onstott, T. C. \& 8 other authors (1999). Dissimilatory reduction of $\mathrm{Fe}(\mathrm{III})$ and other electron acceptors by a Thermus isolate. Appl Environ Microbiol 65, 1214-1221.

Ko, K. S., Lee, N. Y., Oh, W. S., Lee, J. H., Ki, H. K., Peck, K. R. \& Song, J. H. (2005). Tepidimonas arfidensis sp. nov., a novel Gram-negative and thermophilic bacterium isolated from the bone 
marrow of a patient with leukemia in Korea. Microbiol Immunol 49, 785-788.

Kumar, S., Tamura, K. \& Nei, M. (2004). MEGA3: integrated software for molecular evolutionary genetics analysis and sequence alignment. Brief Bioinform 5, 150-163.

Mesbah, M., Premachandran, U. \& Whitman, W. B. (1989). Precise measurement of the $\mathrm{G}+\mathrm{C}$ content of deoxyribonucleic acid by highperformance liquid chromatography. Int J Syst Bacteriol 39, 159-167.

Moreira, C., Rainey, F. A., Nobre, M. F., da Silva, M. T. \& da Costa, M. S. (2000). Tepidimonas ignava gen. nov., sp. nov., a new chemolithoheterotrophic and slightly thermophilic member of the betaProteobacteria. Int J Syst Evol Microbiol 50, 735-742.

Nielsen, P., Fritze, D. \& Priest, F. G. (1995). Phenetic diversity of alkaliphilic Bacillus strains: proposal for nine new species. Microbiology 141, 1745-1761.

Nunes, O. C., Donato, M. M. \& da Costa, M. S. (1992). Isolation and characterization of Rhodothermus strains from S. Miguel, Azores. Syst Appl Microbiol 15, 92-97.

Prado, A., da Costa, M. S. \& Madeira, V. M. C. (1988). Effect of growth temperature on the lipid composition of two strains of Thermus sp. J Gen Microbiol 134, 1653-1660.
Rainey, F. A., Ward-Rainey, N., Kroppenstedt, R. M. \& Stackebrandt, E. (1996). The genus Nocardiopsis represents a phylogenetically coherent taxon and a distinct actinomycete lineage: proposal of Nocardiopsaceae fam. nov. Int J Syst Bacteriol 46, 1088-1092.

Santos, M. A., Williams, R. A. D. \& da Costa, M. S. (1989). Numerical taxonomy of Thermus isolates from hot springs in Portugal. Syst Appl Microbiol 12, 310-315.

Sharp, R. J. \& Williams, R. A. D. (1988). Properties of Thermus ruber strains isolated from Icelandic hot springs and DNA: DNA homology of Thermus ruber and Thermus aquaticus. Appl Environ Microbiol 54, 2049-2053.

Sörbo, B. (1987). Sulfate: turbidimetric and nephelometric methods. Methods Enzymol 143, 3-6.

Tindall, B. J. (1989). Fully saturated menaquinones in the archaebacterium Pyrobaculum islandicum. FEMS Microbiol Lett 60, 251-254.

Westley, J. (1987). Thiocyanate and thiosulfate. Methods Enzymol 143, 23-25.

Williams, R. A. D. \& da Costa, M. S. (1992). The genus Thermus and related microorganisms. In The Prokaryotes, 2nd edn, pp. 3745-3753. Edited by A. Balows, H. G. Trüper, M. Dworkin, W. Harder \& K.-H. Schleifer. New York: Springer. 